\title{
Research Paper: Proximal Interphalangeal Joint Flexion Contracture Treatment by Serial Casting Method and the Use of Thermoplastic Tape
}

\author{
Maryam Farzad $^{1^{*}}$ (D), Mokhtar Arazpour ${ }^{2}$ (D), Erfan Shafiee ${ }^{1}$ (D), Fereydoun Layeghi ${ }^{3}$ (D), Deborah A. Schwartz \\ 1. Department of Occupational Therapy, University of Social Welfare and Rehabilitation Sciences, Tehran, Iran. \\ 2. Department of Orthotics and Prosthetics, University of Social Welfare and Rehabilitation Sciences, Tehran, Iran. \\ 3. Department of Clinical Sciences, University of Social Welfare and Rehabilitation Sciences, Tehran, Iran \\ 4. Department of Occupational Therapy, Orfit Industries, Touro University, Vallejo, California, USA.
}

\begin{tabular}{|c|c|}
\hline $\begin{array}{l}\text { Use your device to scan } \\
\text { and read the article online }\end{array}$ & Cftation Farzad M, Arazpour M, Shafiee E, Layeghi F, Schwartz DA. Proximal Interphalangeal Joint Flexion Contracture \\
\hline 마라물 & $\begin{array}{l}\text { Treatment by Serial Casting Method and the Use of Thermoplastic Tape. Iranian Rehabilitation Journal. 2019; 17(1):75-80. } \\
\text { http://dx.doi.org/10.32598/irj.17.1.75 }\end{array}$ \\
\hline 口istin: & doli http://dx.doi.org/10.32598/irj.17.1.75 \\
\hline
\end{tabular}

Article info:

Received: 27 Aug 2018

Accepted: 14 Jan 2019

Available Online: 01 Mar 2019

\section{Keywords:}

Flexion contracture,

Cylindrical serial casting,

Thermoplastic material,

Proximal Interphalangeal Joint

\section{ABSTRACT}

Objectives: Flexion contractures of the Proximal Interphalangeal joint are the most frequent complications resulting from surgical procedures and traumatic events. Orthotic interventions for the treatment of contractures may include serial splinting, serial casting, dynamic or static progressive orthoses, or a combination of these orthoses. This study aimed to determine the effects of serial casting methods using thermoplastic tape in the Proximal Interphalangeal (PIP) joint flexion contracture treatment.

Methods: Thirty-one patients with flexion contracture of the PIP joint (mean: $32.5^{\circ}$, range: 10 $65^{\circ}$ ) were treated by serial casting method using thermoplastic tape. Flexion contracture, total active motion, extension lag and flexion gap were evaluated in the first session. The affected joint was casted after hand therapy interventions. Patients were requested to visit the clinic every other day for recasting and receiving exercises.

Results: After one month, the mean range of flexion contracture decreased from $32.5^{\circ}$ to $10.7^{\circ}$. The mean range of flexion gap decreased from $3.2 \mathrm{~cm}$ to $1.8 \mathrm{~cm}$. The mean range of extension lag decreased from $2.04 \mathrm{~cm}$ to $0.86 \mathrm{~cm}$, and the mean range of total active motion increased from $81.67^{\circ}$ to $128.81^{\circ}$. All of the aforementioned changes were statically significant $(\mathrm{P}<0.05)$.

Discussion: The use of thermoplastic tape for serial casting is an effective and reliable method for the treatment of PIP joint flexion contracture.

\section{* Corresponding Author:}




\section{Highlights}

- Flexion contracture of fingers is treated with a casting method.

- Casting with plaster of Paris is effective in reducing contracture but it may produce some complications.

- Thermoplastic materials are new casting materials that have benefits for serial casting.

\section{Plain Language Summary}

Flexion contracture of proximal interphalangeal joints of hand is a common condition resulting from injuries and trauma to hand. Sports injuries, finger and hand fractures, and tendon injuries might result in fixed flexion contracture. There are several ways to treat finger flexion contracture. One of the most effective treatments is serial casting. Serial casting with Plaster of Paris (PoP) material was used commonly in the past. Most recently with the improvement of available material for orthotic interventions, thermoplastic materials are more popular among therapists.

Using PoP causes a wide range of complications, such as skin lesions, limiting patient's performance in the activity of daily living, lack of patient's adherence to treatment, and so on. Thermoplastic material due to its antibacterial feature could resolve these problems. In this study, we decided to use thermoplastic tape instead of PoP to see if it is a good substitute for PoP. The results of this study revealed that using thermoplastic material is as effective as PoP in reducing flexion contractures of the finger. Furthermore, the patient's limitation reduces by the use of this type of material. The study patients were also satisfied using this kind of orthosis and report fewer skin complications. Therefore, thermoplastic material is a good choice for patients and therapists.

\section{Introduction}

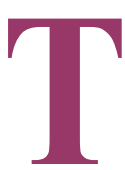

he stiffness of finger joints is a prevalent complication following surgical procedures or traumatic events. The Proximal Interphalangeal (PIP) joints are particularly prone to stiffness and often develop flexion contractures [1]. This may be due to injuries to the joint surrounding tissues, the joint, edema, and poor positioning during immobilization after surgical procedures [2].

Significant improvements in regaining the range of motion in joints are often achievable through exercises and orthotic interventions [3]. Orthotic interventions vary from cylindrical serial casting method to dynamic orthotics. Modified Weeks Test (MWT) is a reliable method for therapists to decide which type of splint/orthotic is suitable for patients based on the joint responses to therapeutic interventions [4].

Dynamic orthoses with the use of traction devices, such as rubber bands or elastic threads, provide an extension in an affected joint and facilitate its flexion. Dynamic orthoses produce plastic deformation through creep. If the tissue is unloaded before failure occurs, it remains permanently lengthened as a result of its viscoelastic properties [5]. Serial static (serial casting) or static progres- sive splints through the prolonged, constant load, can cause plastic tissues deformation via different processes [6] (stress relaxation).

The use of Plaster of Paris (POP) for serial casting method was first introduced by Paul Brand in India in the 1960s for treating stiff joints. As described by Brand, the technique is not a progressive stretching, but of growth. The cells of contracted tissue are stimulated to grow and become internally rearranged or modified by being held in maximum extension [7]. This process is time-consuming and the position of stiff joint must be held constant until remodeling occurs $[8,9]$.

The current research investigated the efficacy of serial casting method, using thermoplastic material instead of POP, in treating fixed PIP joint flexion contractures (regardless of the specific precipitating event). We also hypothesized that this intervention can increase the flexion range of motion and consequently decrease flexion contracture and flexion gap.

\section{Methods}

A power analysis indicated that a total sample size of 27 participants would provide $80 \%$ power with the alpha level of 0.05 to detect a medium effect size. To account 
for an expected loss of $20 \%$ to $25 \%$ of patients, we enrolled 35 patients into this intervention.

The patients who gained $5-10^{\circ}$ increase in passive ROM after therapeutic interventions in one session (heat, stretching and exercises) were included to be treated by serial casting method based on MWT [10]. The patients whose range of motion in the PIP joint increased more than $10^{\circ}$ after the intervention or were unable to complete the therapeutic sessions or refused to participate in the study were excluded.

Finally, 31 adult patients with a flexion contracture of the PIP joint completed the study between May 2015 and February 2016. All individuals provided a written informed consent form prior to conducting the study. The Medical Ethics Committee of the University of Social Welfare and Rehabilitation Sciences approved the study protocol. Thirty-one patient with the Mean \pm SD age of $33.94 \pm 15.20$ years participated in the study. Eleven (35.5\%) patients were women and 20 (64.5\%) were men (Table 1).

The mean measure of active PIP motion was $81.6^{\circ}$; (ranging from $10-179^{\circ}$ ). The average level of flexion contracture was $32.5^{\circ}$ (ranging from $10-65^{\circ}$ ), and the average flexion gap was measured as $3.2 \mathrm{~cm}$ (ranging from $0.5 \mathrm{~cm}$ to $8.0 \mathrm{~cm}$ ).

All patients with flexion contracture in their fingers were evaluated for an active and passive range of motion, as well as the degree of flexion contracture and flexion gap in the first session. After conducting a 45-minute therapeutic intervention, the patients were reevaluated, and those who gained $\leq 10^{\circ}$ in the extension of PIP were enrolled into the study. Patients were visited every other day. After conducting the therapeutic interventions (paraffin wax, oil massage and passive and active joint exercises), PIP joint was casted in the newly gained range of motion.

Orficast thermoplastic tape was used instead of POP. The material was activated in hot water $\left(68^{\circ} \mathrm{C}\right)$ for about one minute. During molding the material for casting the PIP joint, patients were requested to keep their hands in plus position to facilitate intrinsic muscles activities, to gain the most extension range of motion. After removing the Orficast from the hot water, it was gently dried with a towel and, molded on the patient's finger by wrapping and overlapping each layer to cover $50 \%$ of the previous layer (Figure 1).
The affected finger was positioned in maximum possible extension with the MCP joint held in flexion. After 1 minute, the material was sufficiently hardened and could be removed for trimming as needed. The finger's skin color and circulation were evaluated at this time. If the splint was too tight, a new one was fabricated. All orthotic interventions were performed by an experienced occupational therapist.

After one month, the patients were reevaluated in terms of the range of total active motion, the contracture degree, extension lag and flexion gap. The range of motion was measured by a handheld Jamar goniometer placed on the dorsum of the finger. Flexion gap was measured using a ruler as the vertical distance from the tip of the finger to the distal palmar crease while the patients tried to make a fist.

Continuous variables (the active PIP range of motion, the degrees of contracture, flexion gap and extension lag) were compared before and after conducting the intervention by Paired Samples t-test. Spearman's correlation coefficient was used to detect the relation between dependent variables and independent categorical variables. Pearson's correlation coefficient was also used to detect the relation between continuous variables. Analysis of Variance (ANOVA) was applied to detect the differences between outcome measurements in the three groups of patients based on their referral time. SPSS was used for data analysis.

\section{Results}

The pre-test Mean \pm SD score of flexion contracture was $32.5 \pm 14.3$. After conducting the intervention, it decreased to $11.6(=8.2)$. The mean range of flexion gap decreased to $1.43^{\circ}$ (from $3.29 \pm 1.71$ to $1.86 \pm 1.07$ ). The difference in the active range of motion was statistically significant before and after the treatment $(\mathrm{P}=0: 001$, effect size: $\mathrm{d}=1.09)$ (Table 2). The difference in TAM $(\mathrm{P}=0.001)$,

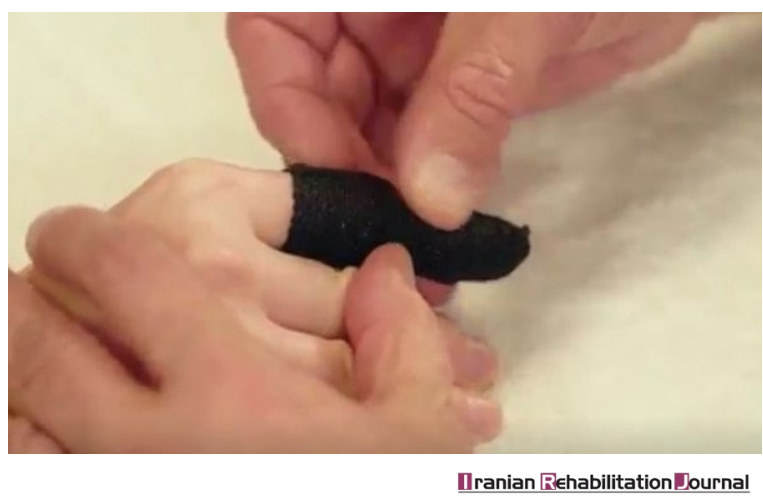

Figure 1. Wrapping Orficast over the patient's finger 
Table 1. Demographic characteristics of the patients

\begin{tabular}{|c|c|c|}
\hline \multicolumn{2}{|c|}{ Variables } & \multirow{2}{*}{$\begin{array}{c}\mathbf{N}(\%) \\
20(64.5)\end{array}$} \\
\hline & Men & \\
\hline Gender & Women & $11(35.5)$ \\
\hline \multirow{2}{*}{ Injured hand } & Right & $14(45.2)$ \\
\hline & Left & $17(54.8)$ \\
\hline \multirow{3}{*}{ Time passed from injury (months) } & $0-6$ & $2(6.5)$ \\
\hline & $6-12$ & $7(22.6)$ \\
\hline & $\geq 12$ & $22(71)$ \\
\hline \multirow{4}{*}{ Total active motion at the baseline } & Excellent & $2(6.5)$ \\
\hline & Good & $3(9.7)$ \\
\hline & Fair & $6(19.4)$ \\
\hline & Poor & $20(64.5)$ \\
\hline
\end{tabular}

Iranian Rehabilitation Journal

flexion contracture $(\mathrm{P}=0.001$, effect size: $\mathrm{d}=2.23)$, extension lag $(\mathrm{P}=0.000)$ and flexion gap $(\mathrm{P}=0.000)$ were statistically different before and after casting (Table 3 ).

There were no difference in TAM before and after interventions with regards to gender $(\mathrm{P}=0: 5$, Spearman's rho $=-0.12)$, age $(\mathrm{P}=0: 7$, Pearson's $\mathrm{Rho}=-0: 15)$, and time past from injury $(\mathrm{P}=0: 7$, Spearman's $\mathrm{Rho}=-0.5)$ in all patients. The difference in flexion contracture was statistically significant $(\mathrm{P}=0: 001$, effect size, $\mathrm{d}=2.23)$. Outcome measurements were independent from time passed from injury based on ANOVA results $(\mathrm{P}>0.05)$.

Table 2. Frequency of TAM after the treatment based on strickland criteria

\begin{tabular}{ccccc}
\hline & Variables & & \multicolumn{2}{c}{$\%$} \\
\cline { 3 - 4 } & & & Before & After \\
\hline \multirow{3}{*}{ Total active motion } & Excellent & 6.5 & 45.5 \\
& Good & 9.7 & 9.7 \\
& Fair & 19.4 & 32.3 \\
& Poor & 64.5 & 12.9 \\
\hline
\end{tabular}

Table 3. Differences between variables at pre-test and post-test

\begin{tabular}{cccc}
\hline \multirow{2}{*}{ Variables } & \multicolumn{2}{c}{ Mean \pm SD } & P \\
\cline { 2 - 4 } & Before & After & 0.001 \\
\hline TAM & $81.67 \pm 39.85$ & $128.81 \pm 38.35$ & 0.000 \\
\hline Flexion gap & $3.29 \pm 1.71$ & $1.86 \pm 1.07$ & 0.000 \\
\hline Extension lag & $2.04 \pm 1.22$ & $0.86 \pm 0.71$ & 0.001 \\
\hline
\end{tabular}




\section{Discussion}

Flexion contractures can be treated by various kinds of orthotic or exercises, regardless of their causes. When the soft tissue is responsible for the contracture, it can be treated with orthotics. When the major problem is in the joints, it is suggested to use total end range time to keep the joint in its maximal tolerable range with continuous stress in the long term [11]. Cylindrical serial static method is among the treatment choices of this condition. The issue is always irritation of skin by POP during the long-time immobilization needed for treatment [12] (one month). Finding a substitution method to overcome this problem can help the patients and clinicians.

Our findings suggest that holding the contracted tissue over time can reduce contracture [13], which is consistent with previous studies $[14,15]$. Many authors believe that long-term immobilization should be avoided due to the risk of losing motion. This idea does not hold merit with regards to the stiff joints and adherent tissues of hand and fingers. When live tissue is held under constant stress, more collagen will be produced; the tissue will overcome the adherence, and improvements in the range of motion will be noticeable [8].

A study on using plaster casts for the elbow, wrist, and finger flexion contractures, reported significant improvements in the range of motion [15]. Serial casting in the PIP joint was also reported to be beneficial in patients with rheumatoid arthritis, leading to improvements in their range of motion and decrease in their contractures [16]. Use of casting for 8 weeks, to manage crush injuries significantly improved the range of motion and decreased flexion contracture [17]. The benefit of using casting instead of dynamic orthosis was also reported [18]. This theory claims that the increased range of passive motion in a stiff joint is proportional to the amount of time the joint is held at its end range position, or total end range time.

Increasing joint flexion range of motion and decreasing contracture suggested the effectiveness of using this method for treating fixed contractures. Our results supported that this method can be used for the patients regardless of the time passed from their injury. Findings of this study confirmed that this method can be used on all genders and age categories. Besides the measured variables, we received no report of skin irritation. Moreover, patients were able to perform their Activities of Daily Living (ADL) with minimal limitations and precautions. The patients were also able to wash their hands during the day. There are some reports on the limitations and problems with using POP [19], which can be eliminated with the use of Orficast.

The obtained results declared that cylindrical serial casting method with the use of thermoplastic tape is effective in the treatment of PIP joint flexion contractures, as well as using POP with fewer limitations.

We disregarded any criteria to evaluate satisfaction and skin irritation in the patients. The lack of a functional evaluation fails to provide important patient information on how the contracture interferes with ADL and how the use of an orthosis contributes to improvements. The lack of a control group or a parallel treatment group using POP was another limitation to this study.

\section{Conclusion}

Cylindrical serial casting can be considered in treating flexion contractures. Thermoplastic materials are appropriate substitutions for POP, without causing any longterm skin irritations.

\section{Ethical Considerations}

\section{Compliance with ethical guidelines}

The Medical Ethics Committee of the University of Social Welfare and Rehabilitation Sciences approved the study protocol.

\section{Funding}

This article extracted from a research project in USWR.

\section{Authors contributions}

All authors contributed in preparing this article.

\section{Conflict of interest}

The authors declare no conflict of interest.

\section{Acknowledgements}

We would like to thank Mr. Steven Cuypers, the chief executive officer of Orfit Industries Company for his support in providing Orfit/Orficast thermoplastic material for fabricating splints. 


\section{References}

[1] Lutz K, Pipicelli J, Grewal R. Management of Complications of Extensor Tendon Injuries. Hand Clinics. 2015; 31(2):301-10. [DOI:10.1016/j.hcl.2014.12.006] [PMID]

[2] Tocco S, Pedrazzini A, Pogliacomi F. Clinical approach in PIPj flexion contracture conservative treatment: Our experience. Acta Bio Medica Atenei Parmensis. 2016; 87(1-S):101-11. [PMID]

[3] Glasgow C, Tooth LR, Fleming J. Mobilizing the stiff hand: Combining theory and evidence to improve clinical outcomes. Journal of Hand Therapy. 2010; 23(4):392-401. [DOI:10.1016/j. jht.2010.05.005] [PMID]

[4] Ng CY, Oliver CW. Fractures of the Proximal Interphalangeal joints of the fingers. The Journal of Bone and Joint Surgery. British Volume. 2009; 91(6):705-12. [DOI:10.1302/0301620X.91B6.21953]

[5] Glasgow C, Tooth L, Fleming J. Which splint? Dynamic versus static progressive splinting to mobilise stiff joints in the hand. The British Journal of Hand Therapy. 2008; 13(4):104 10. [DOI:10.1177/175899830801300401]

[6] Lucado AM, Li Z, Russell GB, Papadonikolakis A, Ruch DS. Changes in impairment and function after static progressive splinting for stiffness after distal radius fracture. Journal of Hand Therapy. 2008; 21(4):319-25. [DOI:10.1197/j. jht.2008.01.002] [PMID]

[7] Callahan AD. Hand rehabilitation and the American Society of Hand Therapists: A decade of progress. Journal of Hand Therapy. 1988; 1(2):53-7. [DOI:10.1016/S0894-1130(88)80047-4]

[8] Boyd AS, Benjamin HJ, Asplund C. Principles of casting and splinting. American Family Physician. 2009; 79(1):16-22. [PMID]

[9] Colditz JC. Plaster of Paris: The forgotten hand splinting material. Journal of Hand Therapy. 2002; 15(2):144-57. [DOI:10.1053/hanthe.2002.v15.015014] [PMID]

[10] Flowers KR. A proposed decision hierarchy for splinting the stiff joint, with an emphasis on force application parameters. Journal of Hand Therapy. 2002; 15(2):158-62. [DOI:10.1053/hanthe.2002.v15.015015] [PMID]

[11] Flowers KR, LaStayo P. Effect of total end range time on improving passive range of motion. Journal of Hand Therapy. 1994; 7(3):150-7. [DOI:10.1016/S0894-1130(12)80056-1]

[12] Bullen M, Kinealy J, Blanchard R, Rodda C, Pivonka P. Comparison of the moulding ability of Plaster of Paris and polyester cast material in the healthy adult forearm. Injury. 2017; 48(11):2586-9. [DOI:10.1016/j.injury.2017.08.010] [PMID]

[13] Freiberg A. Management of Proximal Interphalangeal joint injuries. Canadian Journal of Plastic Surgery. 2007; 15(4):199203. [DOI:10.1177/229255030701500407] [PMID]

[14] Glasgow C, Wilton J, Tooth L. Optimal daily total end range time for contracture: Resolution in hand splinting. Journal of Hand Therapy. 2003; 16(3):207-18. [DOI:10.1016/S08941130(03)00036-X]

[15] Michlovitz SL, Harris BA, Watkins MP. Therapy interventions for improving joint range of motion: A system- atic review. Journal of Hand Therapy. 2004; 17(2):118-31. [DOI:10.1197/j.jht.2004.02.002] [PMID]

[16] Uğurlu Ü, Özdoğan H. Effects of serial casting in the treatment of flexion contractures of Proximal Interphalangeal joints in patients with rheumatoid arthritis and juvenile idiopathic arthritis: A retrospective study. Journal of Hand Therapy. 2016; 29(1):41-50. [DOI:10.1016/j.jht.2015.11.005] [PMID]

[17] Midgley R. Case Report: The casting motion to mobilize stiffness technique for rehabilitation after a crush and degloving injury of the hand. Journal of Hand Therapy. 2016; 29(3):323-33. [DOI:10.1016/j.jht.2016.03.013] [PMID]

[18] Cantero-Téllez R, Cuesta-Vargas AI, Cuadros-Romero M. Treatment of Proximal Interphalangeal joint flexion contracture: combined static and dynamic orthotic intervention compared with other therapy intervention: A randomized controlled trial. The Journal of Hand Surgery. 2015; 40(5):9515. [DOI:10.1016/j.jhsa.2015.01.005] [PMID]

[19] Szostakowski B, Smitham P, Khan WS. Plaster of Parisshort history of casting and injured limb immobilzation. The Open Orthopaedics Journal. 2017; 11:291. [DOI:10.2174/1874 325001711010291] [PMID] [PMCID] 